Há 60 anos, o Conselho Nacional de Desenvolvimento Científico e Tecnológico (CNPq) implantou o programa de iniciação científica, que permite ao estudante universitário de graduação a vivência em um ambiente científico. Hoje esse programa tem a participação de cerca de 100 mil estudantes universitários em todo o Brasil, dos quais aproximadamente 60 mil são contemplados com bolsas de auxílio por meio do Programa Institucional de Bolsas de Iniciação Científica (Pibic). Em 2004, o CNPq lançou o Programa de Iniciação Científica Junior (Pibic-Jr), nos moldes do programa já existente, que permite o treinamento científico de estudantes do ensino médio e profissional. Esse programa tem atualmente 10 mil bolsistas. Posteriormente, o CNPq lançou o Programa Institucional de Bolsas de Iniciação em Desenvolvimento Tecnológico e Inovação (Pibit), que conta atualmente com cerca de quatro mil bolsas. Devemos louvar essas iniciativas virtuosas.

Temos notáveis iniciativas no ensino de ciências e na educação científica no país. Atrair e estimular talentos para termos uma massa crítica de recursos humanos para o desenvolvimento científico e tecnológico do Brasil é uma missão do presente que garantirá um futuro virtuoso para as próximas gerações de brasileiros. O ensino de qualidade, especialmente no nível fundamental, que é o nível que mais afeta a cidadania, deve ser visto como um compromisso de todo o país, em todas as suas instâncias e segmentos. Para uma sociedade democrática, que tem como pressuposto o oferecimento de oportunidades iguais para todos, trata-se de uma missão fundamental.

Isaac Roitman éprofessor emérito da Universidade de Brasília (UnB) e da Universidade de Mogi das Cruzes (UMC), pesquisador emérito do CNPq, membro do Núcleo de Estudos do Futuro da UnB e dirigente do "Movimento 2022 - o Brasil que queremos".

\section{A SBPC NA FORMAÇÃO DE UM PESQUISADOR E GESTOR DE CET}

Aldo Malavasi

COMEÇANDO A HISTÓRIA Tenho clara a imagem do professor Domingos Valente no distante ano de 1969, no estacionamento do edifício da zoologia (formalmente denominado edifício Ernst Markus) na cidade universitária da USP (Universidade de São Paulo), conversando com um grupo de calouros - entre os quais eu me incluía - sobre a SBPC (Sociedade Brasileira para o Progresso da Ciência). Ele era então o secretário-geral da entidade e explicava com a sua voz estridente o que ela era e como ocorriam as suas reuniōes anuais. A SBPC funcionava então em uma sala acanhada, cedida pelo Departamento de Fisiologia Animal, que era chefiado por Paulo Sawaya, um dos fundadores da SBPC. Tinha apenas uma funcionária, uma baixinha muito simpática, a querida Eliana, que ficou na SBPC até 1988.

Como resultado daquela conversa de convencimento, um grupo de alunos do primeiro ano do curso de ciências biológicas decidiu participar da 21 $1^{\text {a }}$ Reunião Anual da SBPC em Porto Alegre, no campus da UFRGS (Universidade Federal do Rio Grande do Sul), no mês de julho de 1969, mesmo sem ter-obviamentequalquer trabalho a apresentar. A longa viagem de ônibus foi uma grande aventura e estávamos todos felizes com a perspectiva de participar de um evento com grandes nomes da ciência brasileira. A partir daí, as reuniōes anuais passaram a ser obrigatórias para mim como estudante e estagiário do Departamento de Biologia (hoje Genética e Evolução), chefiado por Crodowaldo Pavan.

A SBPC de então era dominada pelas hard sciences, especialmente a genética e a física. Dos sete cargos da diretoria do biênio 1975-77, cinco deles eram ocupados por geneticistas (Pavan, Newton Freire-Maia, Luiz Edmundo Magalhães, Eliane Azevedo e Renato Basile), um físico, o presidente Oscar Sala, e uma psicóloga, Carolina Bori. A tesouraria foi, por muito tempo, ocupada por geneticistas do Departamento de Biologia da USP e meus professores Renato Basile, André Perondini e Luis Carlos Simôes. 
Quando me tornei docente no mesmo departamento, em 1973, me associei ao grupo de pesquisa liderado por Pavan e Antonio Brito da Cunha, que estudava a genética de insetos. Pavan, com sua enorme visão, convenceu dois docentes - João Morgante e eu - a nos dedicarmos ao estudo das moscas-das-frutas verdadeiras, não às drosófilas ou às Rhyncoschiara, já que as primeiras causam sérios problemas econômicos ao mesmo tempo que são excelente material de estudo de genética e evolução. Essa mudança de material de estudo foi o mais importante fator da minha carreira científica. A influência do genial e até certo ponto espalhafatoso Pavan marcou de forma definitiva minha forma de pensar e de fazer ciência, bem como de conduzir as relações no trabalho. Ele sempre me dizia para enxergar uma faceta diferente daquela óbvia que todos enxergavam. Ouvi dele inúmeras vezes, em diferentes situações: "Pense e enxergue diferente, italiano", principalmente quando eu discordava de forma acirrada de algumas das suas ideias exóticas, para não dizer malucas.

Comecei a participar das reuniōes da SBG (Sociedade Brasileira de Genética), que tratavam dos assuntos relacionados com as pesquisas que eu tocava dentro da USP, mas também participava das reuniōes anuais da SBPC, que eram carregadas de alto conteúdo político. A famosa 29a Reunião Anual, de julho de 1977, realizada na PUC-SP (Pontifícia Universidade Católica de São Paulo), foi um marco na luta contra o regime militar e um divisor de águas dentro da SBPC, que começou a receber forte influência das ciências sociais e humanas. Interessante notar, entretanto, que somente no biênio 1981-83 aparece o primeiro cientista social na diretoria, José Albertino Rodrigues, como secretário-geral.

\section{O INÍCIO NA ORGANIZAÇÃO DAS REUNIÕES ANUAIS DA}

SBPC A partir de 1983, a convite de André Perondini, então membro da diretoria, comecei a trabalhar na coordenação de audiovisual das reuniōes anuais da SBPC: São Paulo, Belo Horizonte, Curitiba, Brasília. Aprendi o que era a retaguarda e infraestrutura de uma reunião com cinco a dez mil participantes. Tínhamos que garantir o funcionamento tranquilo com mais de 100 monitores de sessões, que acompanhavam todas as atividades dando suporte para que tudo corresse dentro da normalidade e prevenir que ocorressem contratempos. E como ocorriam! Projetores que queimavam (a lâmpada e o próprio) no meio da apresentação; tomadas sem energia; salas que não estavam escuras o suficiente para as projeçôes de slides (lembram dos slides?); apresentadores que simplesmente não apareciam; monitores que eram maltratados e desrespeitados pelos palestrantes. Realmente aprendi bastante começando numa atividade essencial para qualquer reunião científica.

Daí para ser eleito secretário regional de SP em 1986 foi um pequeno pulo. Foi quando comecei a trabalhar diretamente com Carolina Bori, minha grande shadow (isso quando o conceito ainda não estava bem estabelecido) dentro da SBPC. Aprendi extraordinariamente com ela - calma, segura, ouvindo atentamente o interlocutor e sempre tendo uma atitude positiva. Ao lado de Pavan, Carolina foi a figura que mais influenciou minha carreira profissional.

A CARREIRA NA USP O Departamento de Genética da USP era um ambiente de grande efervescência científica com uma variedade de laboratórios que incluía genética humana e médica, genética e citogenética de insetos de várias espécies (incluindo as nossas moscas-das-frutas), genética de primatas, citogenética de roedores, genética de peixes, cultura de tecidos de insetos e genética de microrganismos. O número e a qualidade dos alunos de pós-graduação eram extraordinários. Vivíamos num ambiente de muita criatividade e também, como pode se esperar, de muita competição.

Como nosso laboratório era especializado em moscasdas-frutas de interesse econômico, nos anos 1980 fomos procurados pelo Departamento de Agricultura dos Estados Unidos (USDA) para que realizássemos estudos no nordeste do Brasil para demonstrar que a área produtora de melóes era livre de uma espécie de mosca-das-frutas. Esse trabalho se desenvolveu muito bem e conseguimos demonstrar que a região noroeste do estado do Rio Grande do Norte era (e permanece até hoje) livre de Anastrepha grandis, a mosca alvo que ataca frutas da família das cucurbitácaeas - melóes, 
abóboras e afins. O trabalho foi realizado por demanda e com forte apoio do setor produtivo, e por isso foi necessária muita negociação internacional para a demonstração da área livre. Esse foi o meu debut como negociador em nível internacional, discutindo em Washington e Roma o estabelecimento da área que acabou sendo reconhecida em 1988.

Esse projeto foi um importante passo para deixar a segurança do laboratório dentro do campus universitário da USP e ir para o mundo externo, onde a realidade é bem diversa. $\mathrm{O}$ que hoje se espera da universidade brasileira - a abertura para a sociedade como um todo - era visto com reservas há 30 anos. Realizar pesquisas voltadas para melhorar a competitividade do setor privado, então, era quase um pecado capital.

No final dos anos 1990, os produtores de manga brasileiros não podiam exportar aos Estados Unidos e Japão por barreiras fitossanitárias - basicamente, pela presença de moscas-das-frutas nas regiōes produtoras. Desenvolvemos então, para essas pragas, em parceria com a Embrapa (Empresa Brasileira de Pesquisa Agropecuária), USDA e associação de produtores, o tratamento hidrotérmico que abriu as portas para a exportação de mangas do Brasil para esses dois importantes mercados consumidores, gerando uma receita significativa para o país e centenas de empregos, além de melhorar a qualidade da fruta para o consumo interno. A aprovação do tratamento demandou longas e cansativas reuniōes em Washington e Tokyo que mesclavam interesses econômicos, técnicos e até científicos. Foi um grande treinamento para todos nós na arena internacional.

Com as pesquisas que tocávamos no laboratório, de interesse econômico para o Brasil, conseguíamos formar mestres e doutores de várias regiōes do país que, por sua vez, começaram novos laboratórios em suas instituições. A publicação dos resultados desses trabalhos em periódicos e a participação em reuniōes científicas da área inseriram o laboratório e o Brasil no cenário internacional. A escalada foi natural até que atingi o nível de professor titular da USP, em 1995.

ALÉM FRONTEIRAS O pós-doutorado é algo que realmente abre a cabeça dos jovens doutores que se isolam nos seus laboratórios durante a pós-graduação, pressionados pelos orienta- dores para concluir a tese antes do término da bolsa. Como já era docente quando terminei o doutorado eu não enfrentei esse problema, mas o estágio de pós-doutoramento na Universidade do Texas, no distante ano de 1979, foi marcante por entrar em contato com outra cultura científica e social. Ao lado do aprimoramento do inglês, o contato com cientistas das mais diferentes tendências em genética e evolução foi um primeiro passo para entender e respeitar a biodiversidade (aqui considerando a cultura como parte do nosso "bio").

Um novo estágio na Universidade de Massachusetts e USDA em 1989/90 me ajudou a consolidar uma visão mais ampla da ciência, ao mesmo tempo que construiu um amplo networking com pesquisadores e gerentes de projeto espalhados pelo mundo. Próximo ao regresso ao Brasil, recebi o convite para ir trabalhar no USDA em Honolulu, no Havaí, mas declinei, muito penalizado, pois acreditava que estava maduro para ajudar o Brasil na área de genética e controle biológico de insetos pragas. Além disso, a Fapesp (Fundação de Amparo à Pesquisa do Estado de São Paulo), o CNPq (Conselho Nacional de Desenvolvimento Científico e Tecnológico) e a USP haviam investido muito na minha formação e eu me senti no dever de retornar esse investimento para o país.

Gradativamente, começaram a se abrir portas para uma atuação internacional, como chair do Working Group of Fruit Fly of the Western Hemisphere por nove anos, chair do Simpósio Internacional de Moscas-das-Frutas por quatro anos, membro de vários boards de sociedades internacionais e membro de conselhos consultivos científicos ao redor do mundo (Califórnia, México, Guatemala, Etiópia, FAO-Rome), além de missões internacionais em mais de 30 países nas Américas e Caribe, África, Ásia e Europa.

Com essas missões, organizadas por organismos internacionais como a FAO (Food and Agriculture Organization), IAEA (International Atomic Energy Agency), USDA (United States Department of Agriculture), IICA/OEA (Instituto Interamericano de Cooperação na Agricultura da Organização dos Estados Americanos) aprendi a observar e a respeitar as características e a cultura de cada povo, bem como orientar e canalizar a energia para os objetivos do projeto. 
Essas missões tinham o objetivo de traçar estratégias para cada país da melhor forma de ultrapassar as barreiras fitossanitárias - ajudávamos principalmente os países em desenvolvimento. E minha maior colaboração sempre foi romper a imobilidade e colocar diferentes instituições dentro do país - às vezes, competidoras - para trabalhar de forma conjunta para atingir o objetivo comum. Nesse sentido, ser brasileiro ajudava extraordinariamente, pois eu usava exemplos do nosso país para convencê-los a tocar os desafios para frente. Além, obviamente, de falar do futebol, do samba e das praias. E me dei conta de como o Brasil era (e continua sendo) um país muito querido pelo cidadão comum da grande maioria dos países.

Com a participação em conselhos e associações científicas, ganha-se uma experiência extraordinária em negociação e estratégia em ambiente altamente competitivo e com múltiplos interesses envolvidos. Nesses boards e missões participam cientistas de várias áreas, gerentes de projetos que precisam mostrar resultados, membros de governo de diferentes níveis e visões (em geral não alinhadas com a ciência) e setor privado que, surpreendentemente para mim, eram com frequência mais maleáveis e razoáveis que os colegas cientistas.

Em 1997, fui convidado pela OEA a ser o diretor do Programa de Erradicação da Mosca-da-Carambola no norte do América do Sul, compreendendo o Suriname, República da Guiana, Guiana Francesa e o estado do Amapá. Era um projeto muito desafiador, que envolvia enormes problemas políticos com a França - já que a Guiana Francesa ainda é um território ultramarino. Foi muito interessante negociar constantemente com governos de quatro países (com quatro línguas e quatro moedas diferentes), com equipes trabalhando em cada país e implementando o projeto de acordo com as características locais.

O projeto foi bem-sucedido, tendo eliminado a praga na Guiana, quase na totalidade do Suriname e no Amapá. Na reta final aconteceram os ataques terroristas de 11 de setembro de 2011 e as fontes financiadoras secaram. Hoje a praga retomou toda a área que ocupava originalmente.

A experiência de comandar um grande número de técnicos de diferentes nacionalidades e nível cultural e realizar um tra- balho nas cidades distantes e na selva foi realmente enriquecedora. Certamente não se treinam bons marinheiros em mares calmos. E a experiência do Suriname foi pra lá de tempestade.

Eu diria a que a participação nos boards, o programa no Suriname por quatro anos, associada à participação em várias diretorias da SBPC foram as mais ricas experiências que tive na minha vida profissional. Vamos então voltar à SBPC.

AS DIRETORIAS DA SBPC Participei de sete diretorias a partir de 1993 até 2014 (não contínuos), num total de 13 anos trabalhando com os presidentes Aziz Ab Saber, Sérgio Henrique Ferreira, Glaci Zancan, Ennio Candotti, Marco Antonio Raupp e Helena Nader. Fui secretário, secretário-geral e tesoureiro. Fui também conselheiro por duas ocasiōes.

Embora a diretoria tenha nove cargos, sendo um presidente, dois vice-presidentes, um secretário-geral, três secretários e dois tesoureiros, a SBPC é um regime totalmente presidencialista. As principais ações da sociedade são determinadas pelo presidente e se não há acordo dentro da diretoria, o conflito se instala. Eu poderia escrever um volumoso livro sobre meus 13 anos testemunhando disputas sensacionais e estressantes. Para o sócio entretanto, essas desavenças não chegam a atingi-lo seriamente. $\mathrm{O}$ que havia de comum entre todos era o real interesse pela comunidade científica brasileira. Esse é um fenômeno interessante apesar das profundas diferenças entre seus membros, o resultado final era sempre no sentido de promover a ciência e a tecnologia no país da melhor forma possível. Os caminhos variavam, mas o objetivo comum, que era o mais importante, era bem definido.

Há também o conselho da SBPC, que se reúne anualmente durante as reuniōes anuais e, adicionalmente, em fevereiro nos anos de eleição. O grupo estabelece as grandes diretrizes da entidade, mas fica longe do seu dia a dia. E muitas vezes funciona como uma suprema corte, quando as divergências na diretoria estão muito acentuadas.

Um aspecto que deve ser lembrado em relação à SBPC e que raramente ocorre em outras sociedades científicas e similares, é a sua forma de eleição. Os sócios votam em nomes, não em chapas. O resultado disso, algumas vezes, é a composição de diretorias formadas com membros de posições antagôni- 
cas. Isso é interessante-quando não paralisante-, pois resulta num excelente exercício de negociação e acomodação de forças. Apenas para ficar em dois exemplos, numa diretoria fui eleito tesoureiro com precípuo papel de garantir a viabilidade da sociedade e não permitir seu endividamento, que já era alto. Com muito trabalho, stress e desgaste consegui atingir esses objetivos. O outro exemplo, agora oposto - para mim magnífico - é a diretoria eleita para 2007-09 quando dos nove cargos, cinco eram de uma "chapa" e os outros 4 membros da outra "chapa". Sob a liderança do Raupp, com a sua forma tranquila de condução, ao final de alguns meses éramos todos um só grupo com um entendimento acima do normal. Com isso conseguimos avançar em muitos aspectos, como com a aquisição da sede administrativa na rua da Consolação, em São Paulo, que, graças à eficiente gestão do tesoureiro José Raimundo Coelho, colocou a SBPC num patamar de total tranquilidade, já que a sede é um problema recorrente em quase toda sociedade científica no Brasil. E essa diversidade que fazia avançar as várias atividades da SBPC.

Um outro aspecto interessante é a proximidade daSBPC com os órgãos de governo encarregados de traçar e executar a política de ciência e tecnologia nacional. Um dos efeitos disso foram os convites, em diferentes épocas, a vários membros da diretoria e do conselho a assumirem importantes cargos federais. Óbvio que os convites eram feitos em função das carreiras como pesquisadores e cientistas, mas a SBPC dava e dá uma visibilidade aos seus membros. O primeiro foi Pavan, que deixou a presidência da SBPC para a assumir a direção do CNPq em 1986, seguido por Abilio Baeta Neves (Capes), Jorge Guimarães (Capes), Regina Markus (Ministério de Ciência, Tecnologia, MCT), Sergio Rezende (Financiadora de Estudos e Projetos, Finep, e MCT), Marco Antonio Raupp (Agência Espacial Brasileira, AEB, e $\mathrm{MCT}$ ), Celso Melo (CNPq), José Raimundo Coelho (AEB), Renato Janine Ribeiro (Ministério da Educação, MEC), Eunice Durhan (MEC), Reinaldo Guimarães (Ministério da Saúde, MS), João Steiner (MCT).
Esses convites podem e devem ser interpretados como algo natural na atividade política da SBPC. Apesar dessa proximidade com o poder central, a sociedade sempre manteve sua independência, com uma posição crítica em relação às medidas tomadas pelo governo federal na área de ciência e tecnologia. Essa atitude de colocar sempre em cheque as ações governamentais foi e é a grande responsável pela reputação da entidade. Algo bastante similar acontece com a AAAS (American Association for the Advancement of Science) nos EUA - proximidade, mas crítica sempre.

Participar da diretoria da SBPC é uma experiência muito marcante, pois se aprende sobre a diversidade e a riqueza da ciência no Brasil e, claro, suas fragilidades e potencialidades. Com diferentes background científicos, depreende-se a perspectiva de cada ciência e sua forma de se relacionar nas diferentes regiōes do país.

Pelas minhas características pessoais, sou muito mais para carregar piano e dar soluções práticas do que participar de intermináveis reuniōes e gerar documentos longos e de difícil compreensão. Reconheço minha deficiência nos aspectos teóricos - sou realmente de ação. Com isso me dediquei bastante às reuniões anuais, regionais e especiais.

AS REUNIÕES DA SBPC Como o início de minha história na SBPC aconteceu numa reuniāo anual, acabei me interessando em melhor organizá-la e dar maior eficiência e organicidade antes, durante e depois dela ocorrer. O grande desafio de organizar uma reunião é exatamente o fato de ela ser anual. Quando terminamos o relatório de uma reunião, que ocorre em julho, começamos logo depois a organização da seguinte. Com isso, não há muito tempo para refinamento e testes. Esse é o desafio que, em geral, a maior parte dos membros de uma diretoria não gosta de aceitar.

Quando assumi como secretário na gestão do Aziz em 1993, conversava muito com o secretário-geral Ademar Freire-Maia, geneticista como eu, e nos dávamos muito bem para tratar desses assuntos. Já conhecia parcialmente o funciona- 
mento, pois havia trabalhado na comissão de audiovisual nas reuniôes de 1984 a 1988, mas não como organizador - o que começou com o $46^{\circ}$ encontro em Vitória, no Espírito Santo, em 1994. A reunião seguinte foi em São Luís, no Maranhão, e lá comecei a assumir a coordenação-geral com um desafio enorme, pois eram mais de 12 mil inscritos em função de um excelente trabalho realizado pela comissão organizadora local. Uma cena inesquecível foi o tumulto gerado por aqueles que queriam se inscrever a qualquer custo. Como não havíamos feito um número grande de cadernos de programa além daquele dos inscritos previamente - e era inviável imprimir cadernos adicionais em tão pouco tempo (a impressão era feita em São Paulo e o transporte era via caminhão), Aziz e Ademar eram de opinião que não poderíamos aceitar a inscrição sem fornecer o caderno de programa. E vai convencer a multidão... Decidimos então que reduziríamos o valor da inscrição e daríamos apenas o certificado de participação aos recém inscritos. E todos os dias publicávamos nos jornais de São Luís as atividades daquele dia, além de distribuir cartazes no campus da Universidade Federal do Maranhão (UFMA). Foi um excelente aprendizado. Doloroso, mas efetivo.

Com isso, no remoto ano de 1995 começamos um processo de informatização e modernização da secretaria e das reuniōes. Para isso tivemos um forte apoio de Sergio Henrique e de Jacob Palis (então presidente e vice-presidente). Basicamente, conseguimos colocar todos os inscritos numa base de dados que levávamos conosco em dois hard drive - em voos separados -, permitindo uma entrega de material com muito menos espera. O desafio era arranjar microcomputadores e impressoras suficientes, todos ligados em rede, em cada universidade que sediava a reunião anual.

Outro problema enorme era o trauma dos resumos recebidos via correio em um formulário de papel. Imaginem de 2 a 3 mil envelopes que enchiam a sede da SBPC sendo abertos e separados manualmente por sessóes onde seriam apresentados. $\mathrm{E}$ sem nenhuma revisão do que estava escrito! Havia um bom número de trabalhos que se perdiam e que não eram programados.

Começamos com a inscrição e o resumo enviados num disquete (o que é isso mesmo?) que imprimíamos e enviávamos ao comitê de revisão. Esse comitê foi criado depois que li um resumo que tratava da temperatura retal da anta! Foi o gatilho para criarmos um mecanismo para evitar tais absurdos. Contávamos com um grupo de abnegados que se dispunham a ir até o escritório na rua Maria Antônia rever o que tinha sido recebido.

Lutamos muito e conseguimos eliminar a impressão do livro de resumos para entrega durante a reunião anual. Argumento: o não comparecimento dos proponentes que deveriam apresentar seus trabalhos na reunião era ao redor de $12 \%$, mas o resumo aparecia impresso no livro como tendo sido apresentado. Além disso, o livro de resumos era tão grosso e pesado que causava muitos transtornos. Assim, a impressão passou a ser feita a posteriori, apenas com os trabalhos efetivamente apresentados. E de impresso, o livro de resumos evoluiu mais recentemente para apenas publicação eletrônica.

Outra briga bonita foi a eliminação das sessões de comunicação oral. Todos nós das áreas experimentais que frequentavam congressos internacionais sabíamos que as sessões orais quase não existiam para apresentação de trabalhos, tendo sido substituídas por pôsteres, ainda na época sem plotters. Entretanto, as ciências sociais e humanas não tinham qualquer tradição de apresentação em pôster. Fui execrado inúmeras vezes pela minha insistência em acabar com as sessões orais, sendo acusado de querer eliminar essas ciências das reuniōes. O tempo mostrou o acerto da minha insistência e hoje vemos pôsteres de alta qualidade em todas as sessōes de todas as áreas. Para incentivar os autores (basicamente alunos de graduação e pós) a capricharem no pôster, instituímos a comissão de avaliação, onde dois ou três especialistas percorriam a sessão perguntando e fazendo sugestôes aos autores.

Com o advento da internet, eliminamos a inscrição via correio, que passou a ser feita on-line no site da SBPC. Enfrentei muita resistência sob argumento que não havia internet em todos os lugares do país - o que era verdade-, mas havia as lan houses e a possibilidade de usar a rede das universidades. Hoje, escrevendo este artigo, fico feliz ao lembrar que sempre induzi o desenvolvimento de novas tecnologias e procedimentos em prol da SBPC. Aliás, sempre argumentei que não podíamos esquecer do nosso nome as duas últimas letras. 
Introduzimos também outras alterações como: apresentador para os conferencistas (antes o/a conferencista ficava lá na frente sem saber exatamente como proceder); inscrição prévia em minicursos para evitar tumulto no início da reunião (após o advento da internet ampla); a sessão de pôsteres ser única atividade da reunião naquele horário, para valorizar a atividade e não dispersar os participantes; setorização da secretaria por atividades, para permitir especialização e maior eficiência.

Em 2003, quando secretário-geral na gestão de Glaci Zancan (2001-03), introduzi uma temeridade para então: a eleição eletrônica para todos os cargos da SBPC. De novo, o que hoje soa absolutamente normal, me tomou muita negociação, tempo, conversa, convencimento, idas e vindas.

Uma dor de cabeça constante nas reuniōes anuais é a sessão inaugural. Quem vai para a mesa, quem vai discursar, qual a sequência dos discursos? Eram (e imagino que continuam sendo) problemas recorrentes. Aos poucos, as diferentes diretorias estabeleceram um padrão que funcionava relativamente bem desde que não houvesse excesso de pressão da comissão local. Conseguimos reduzir o número de pessoas na mesa e, mais importante, o/a presidente da SBPC sempre fazer o último discurso da sessão inaugural. E não atrasar o início por mais de 20 minutos. Para evitar contratempos e ter maior controle da cerimônia, dispensamos os mestres-de-cerimônias locais e assumimos a função.

Tendo sido o coordenador geral de 11 reuniôes anuais e de 13 reuniōes regionais/especiais, aprendi a receber pressōes divergentes dos vários setores e a acomodá-las; a desenvolver empatia com a comissão organizadora local, nossos parceiros que representam a maior parte dos nossos clientes finais; que é possível obter sempre melhor desempenho da equipe local aceitando suas limitaçōes e respeitando os diferentes backgrounds culturais.

Finalmente, o aspecto de networking e lúdico da reunião anual: fiz uma quantidade enorme de amigos por todos os lugares que passei, aprendi muito sobre o Brasil e sobre as outras ciências. Principalmente nos finais de tarde, nas mesas das áreas de alimentação, com um copo na mão.

A EQUIPE DA SBPC Na realidade, não posso deixar de falar, nesta minha revisão, sobre a equipe da SBPC. Eu diria, sem medo de errar, que o papel da sociedade é tão proeminente hoje muito em função do alto nível de comprometimento do seu staff. Nunca encontrei, em todas as organizações que já trabalhei, tal nível de seriedade, comprometimento e eficiência. Seria difícil aqui dar o crédito a todos que merecem, mas gostaria de destacar alguns, como a Nicinha, que é a história viva da SBPC e com seu jeito calmo e tranquilo sobreviveu a enormes intempéries e passou por 23 diretorias com 11 presidentes! Junta-se a ela a Fernanda, que sempre desconfiava das minhas inovações; a Wanda Marta, para quem tudo ia dar errado; a Lea, detalhista e dedicada, única para a função com os resumos; e mais recentemente Luiz, Thiago e Carlos. Não esquecendo as que nos deixaram pelo caminho, Teló, Zuleica e Tereza. Enfim, não se faz uma sociedade sólida sem um time de suporte forte e coeso.

A MOSCAMEd NO VALE dO SÃO FRANCISCO Após deixar a USP, aceitei mais um desafio interessante: implantar uma biofábrica de insetos estéreis no Nordeste do Brasil, usando o formato de OS (organização social) ligada ao governo do estado da Bahia, contando com forte apoio do MCTI e do MAPA (Ministério de Agricultura e Abastecimento). Assim, em 2005 inauguramos em Juazeiro, Bahia, no vale do rio São Francisco, a primeira biofábrica no país para a produção e liberação de insetos estéreis de pragas da agricultura. Passado algum tempo e com forte apoio do então ministro de Ciência, Tecnologia e Inovação Sergio Rezende, começamos também a produção de mosquitos vetores de doenças humanas.

Enfrentamos enormes dificuldades para colocar e manter a operação de uma OS sem orçamento fixo de qualquer entidade governamental. A busca de sustentabilidade era, e continua sendo, um grande desafio, mas que traz no seu bojo uma experiência única dentro do semi-árido brasileiro. Aprendi muito, negociando com os governos federal, estaduais e municipais, produtores, universidades, organizações internacionais etc., mostrando o papel importante que a Moscamed Brasil realiza para o país como centro irradiador de tecnologia de ponta e de treinamento para técnicos de dentro e de fora do país. Sem ser governo e sem ser empresa privada. 


\section{A AGÊNCIA INTERNACIONAL DE ENERGIA ATÔMICA No início} de 2014, o diretor-geral da Agência Internacional de Energia Atômica da Organização das Nações Unidas (IAEA), Y. Amano, me convidou para ser diretor geral adjunto no departamento que cuida das aplicações nucleares de uso pacífico - entre elas alimento, agricultura, prevenção e tratamento de câncer, ambiente, águas continentais e tecnologia nuclear na indústria. $\mathrm{O}$ trabalho que estava sendo desenvolvido na Moscamed, a minha inserção na comunidade internacional nas áreas de controle genético de pragas e fitossanidade e a minha atuação dentro da SBPC me credenciavam para o posto.

Sair do querido vale do São Francisco e ir morar em Viena por três anos não estava nos meus planos, mas como sempre aceitei o desafio e vim para a Agência basicamente para tocar o projeto de 50 milhões de euros para a renovação e construção dos novos laboratórios, além de tocar as questôes de pesquisa e desenvolvimento (P\&D) do departamento que conta com uma equipe de cerca de 400 pessoas altamente qualificadas de 38 nacionalidades. Foi e tem sido um desafio enorme, que está perto de sua conclusão. Ao invés dos três anos, ficarei quase cinco para terminar esse projeto. A experiência de interagir com mais de 100 países nessa função é fantástica e aprende-se muito a navegar em mares revoltos. Quando converso com os ministros de todas as áreas, estando na sede em Viena ou nos países que visito, percebo como conseguimos atender tantas demandas. Apesar dos mares revoltos é incrível entregar novos laboratórios e ver implementados projetos que fazem a diferença em muitos países da África, Ásia e América Latina. É algo bastante recompensador.

Para terminar, como diria meu mestre Pavan, sou um homem de muita sorte por ter feito tudo que fiz, me divertindo e conhecendo as coisas e as pessoas com quem interagi. Por essas e outras é que a SBPC, aos seus 70 anos, é uma jovem senhora, segura de si, contundente e agradável. Como tem que ser!

Aldo Malavasi é diretor-geral adjunto de Ciências e Aplicaçōes Nucleares da Agência Internacional de Energia Atômica (IAEA) da Organização das Nações Unidas (ONU) em Viena, Austria. Professor titular aposentado do Departamento de Genética da Universidade de São Paulo. Atuou na SBPC como secretário-geral (1999 a 2001, 2007 a 2009 , 2009 a 2011, julho/2013 a março/2014), primeiro tesoureiro (2003 a 2005) e secretário (1993 a 1995 e 1995 a 1997).

\section{PIONEIRAS dA GIÊNGIA NO BRASIL: UMA hISTÓRIA contada DOZE ANOS DEPOIS}

Hildete Pereira de Melo, com colaboração de Ligia Rodrigues

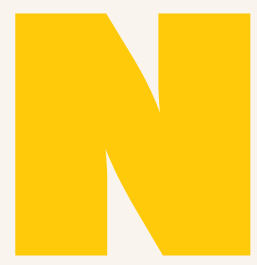
este ano de 2018, a Sociedade Brasileira para o Progresso da Ciência (SBPC) completa 70 anos e a efeméride permite que se possa avaliar a presença feminina nos espaços científicos nacionais através da trajetória da própria SBPC. Esta, como uma das principais sociedades científicas nacionais, expressa muito bem os percalços e os êxitos das mulheres na construção de uma carreira científica no país. Ninguém duvida que a carreira científica foi e é um espaço de poder e masculino, e analisando a história da presidência da associação, vamos encontrar a primeira cientista eleita como presidente da SBPC apenas no final dos anos 1980. A professora Carolina Bori (1924-2004), apesar de ter ingressado na SBPC em 1969, só vinte anos depois foi eleita presidenta da entidade para o mandato de 1987-1989. Dez aos depois, a bioquímica Glaci Zancan (1935-2007) foi eleita para os biênios 1999-2001 e 2001-2003. E, finalmente, na segunda década do século XXI, a biomédica Helena Nader, que já era primeira vice-presidente, acabou assumindo o mandato na gestão de 2011-2013 e em seguida foi eleita presidenta para os mandatos de 2013-2015 e 2015-2017. Convenhamos que na relativa longa vida da SBPC, apenas três mulheres conseguiram galgar a presidência da sociedade e foram presidentas por cerca de seis mandatos bianuais.

Isso não é por acaso. O desenvolvimento científico dos últimos dois séculos, no mundo, foi sempre creditado ao gênero masculino e essa trajetória da SBPC expressa apenas a invisibilidade que, por muito tempo e de forma persistente, se deu em relação à presença feminina nos espaços científicos mundiais e brasileiros. Com essa preocupação, este artigo tem como objetivo traçar o empenho de pesquisadoras feministas que, nos últimos 20 anos, estudam a participação das mu- 